\title{
ECONOMIC GROWTH OF GEORGIA AND SOCIAL PROBLEMS
}

\section{MERAB JULAKIDZE}

\author{
Associate Professor
}

Ivane Javakhishvili Tbilisi State University, Georgia

merab.julakidze@tsu.ge

Abstract. Generalization of macroeconomics dynamic model is mean of multipliable influence in different directions of Technological progress on economic growth, connection between production and its intensification on non-production factors, and optimal component criteria for social-economic intensification process. The Spline structure of Production Function is an efficient tool for establishing the dynamics of its parameters, which, in turn, makes it possible to correlate the efficiency of the production factors and their combination with the potential of the intensification factors: scientific-technical, educational, and organizational. Application of ultimate model for creation of aggregate figures' movement, rates and proportions and reaching of social purposes and their dynamic results: prediction of normative genetic consumption demand calculation on a person, public and state.

KEYWORDS: ECONOMIC GROWTH, TECHNOLOGICAL PROGRESS, GENERALIZATION MACROECONOMIC MODEL, FACTORS OF INTENSIFICATION, SOCIAL STABILITY.

For citation: Julakidze, M., (2021). Economic Growth of Georgia and Social Problems. Globalization and Business. 12, $152-154$. https://doi.org/10.35945/gb.2021.12.020

\section{INTRODUCTION}

The study discusses the topics of developing Georgia's socio-economic development target function and its realization on the macroeconomic level. It is oriented towards maximizing social target accomplishment according to output and its usage in every direction, balancing labor and potentials. The resulting socio-economic macromodel will be used for interpreting base trajectory of Georgia's development as the trajectory closest to the extremum. Based on this, the function was restored in accordance with trajectory and finally the parameters of target function were estimated.

The optimization macromodel in its original form was used for rational distribution of resources in every direction of utilization and accumulation. Also, it was used for calculating rational rates and proportions of social targets. The dynamics of dual variables of the problem were used, more precisely, efficiency norm and its movement in the perspective. The results of socio-economic optimization are analyzed which is compared with the calculation based on production optimization considering technological progress.

The macroeconomic model will take more consistent form if the optimization is directed not towards pure production targets but well-defined social-economic targets as well. Focusing on production target maximization was characteristic of sectoral management process, while social direction was financed based on residual principle. It is well-known that this made production maximization the main objective. Nowadays Georgia is focused on socially oriented market economy, the transition to which has not finished yet. At the scientific level this demands developing tools for defining socio-economic goals and if possible, their quantification which might become a base needed for forming the focus of production system development.

\section{GENERAL FORM OF GEORGIA'S SOCIO-ECONOMIC OPTIMIZATION CRITERION}

The target function entails social welfare and attainment of comprehensive development. Let us characterize welfare at time t:

1. Expanded consumption fund per capita $c^{t}$, which also includes population's capital and current expenditure in the service sector;

2. Average worker's labor time fund as $\chi \mathrm{t}$ share of time. While ultimate wellbeing, which indicates the ultimate level of welfare category, corresponds to maintaining consumption in accordance with rational norms.

Measuring $\mathrm{c}^{t}$ consumption fund in fixed prices (we operate on physical amount of this fund), we will be able to calculate the fund's actual amount $\bar{C}$, by multiplying natural norms of consumption by these fixed prices and summarizing them according to every type of consumption good.

This is how we will get that the comfort condition of an average worker with respect to his/her employment is reached at the target level of working time (for instance, three days of leisure per week).

Therefore, we can equate reaching social consumption targets with reaching such a structure of production and productivity that consumption is c, and time expenditure on labor is $\bar{\chi}$. 
As for the comprehensive social development, we will firstly note that development through regular learning might be attributed to one form of service and be involved in consumption of service or non-productive consumption. There is a social aspect of comprehensive or mainly spiritual development category. It is measured by the quality of scientific-educational and administrative development. Indeed, the higher the share of people prone to these kinds of activities, the higher social intellectual potential will be put at play. This can be considered as an important and economically tangible aspect of spiritual development. Let us denote the share of people employed in scientific-educational and administration spheres (intensification fields) by $\lambda^{t}$, then the general form of the target function at the macro level will take the following form:

$$
U^{t}=U\left(c^{t}, \chi^{t}, \lambda^{t}\right) \rightarrow \max
$$

Specification of the target function should be based on the fact that social targets are dual: consumption, which is measured by consumption level per capita (including consumption of leisure time) - they are characterized by final level, existence of saturation level; and spiritual, which is determined by social structure and not by individuals - they are characterized by theoretical possibilities of indefinite growth, which is given by genetic funds and economy. The final state puts consumption dependence to inferior rather than superior position, which is the case in "consumerist society" and which has a big perspective later, once the final satiation level has been reached.

\section{MODEL REALIZATION}

Traditional macro models - regular Cobb-Douglass production function with autonomous technological progress - take us to diminishing capital-output dynamics, which is its main flaw. It would be interesting to analyze dynamics of capital-output according to general macro model. It turns out that for the optimization variant, which shows us its trajectory, is in reality characterized by increasing capital-output. This may be attributed to qualitative increase of production factors, the representation of which is impossible by neutral technological progress of Tinbergen's factors. Theoretical generalization of economic growth trajectory possibilities with increasing capital-outputs should be discussed as qualitative accomplishment of generalized model.

As we have seen target function and macroeconomic development optimality integral socio-economic parameter have been developed. The evaluation of target function parameters was based on base sections of the trajectory, assuming that the perspective trajectory would continue with the same phase.

Optimality criterion evaluates economic growth in the following two directions:

Welfare might be specified as reaching the final level of non-productive consumption of material goods. With the aim of representing this category in the target function the following indicator was constructed: weighted algorithm of squares of deviation of current and half long-term goods' factual con- sumption from its normative level. To this indicator an analogous sum should be added which will measure social effects of deviation from normative levels of long-term consumer goods and real term representation of social infrastructure funds.

Spiritual development condition with first estimation can be reduced to two indicators: labor time fund per worker and development of educational, scientific, cultural and administrative fields (according to relative employment level in them). Apart from this, state consumption maximization (in certain proportions) might be ascribed to the overall objective of economic development.

Model may not be used for direct calculations without estimation of optimality criterion parameters. The values of these parameters are chosen so that extremum point in the base interval will best correspond to trajectory. For this, an inverse problem of the original optimization will be solved in the retrospect.

For solving the inverse as well as the original problems the package for nonlinear optimization analysis of economic models was used.

Basic and dual variables of the original problem, as well as its optimality conditions largely exceed unknown parameters of the target function. This means that the inverse function is over specified. For these circumstances the parameters were found under the condition that the sum of squares of derivatives of Lagrange function of the original problem according to its basic and dual variables will reach minimum. After prolonging target function parameter estimates in the perspective the original problem was transformed into a classic problem of nonlinear conditional optimization which was solved using the above-mentioned package. Solving the direct optimization problem yielded macroeconomic forecast indicators of Georgia's socio-economic development. This allows us to analyze main trends of the country's development.

Economic sustainability of GDP growth rates depends on GDP expenditures, or the growth structure of economy and its productivity. The higher the share of investment in capital and the lower its share in private consumption with respect to GDP, the higher the economic sustainability and consequently, quality of economic growth. Georgian economy is characterized by excessive consumption (absorption), which means that domestic demand exceeds the good and service supply capacities of the local economic sector. The overall demand is very high and constitutes $85 \%$ of the total GDP which is an indication of low-quality growth. When the ratio of consumption and saving is leaned in favor of the former it means that current generation is living at the expense of the future generations which will negatively affect wellbeing of the latter. This means that we are consuming more than we should.

Resolution of the optimization problem resulted in obtaining forecasting indices of macroeconomic dynamics that permit an analysis of the main development trends in Georgia's national economy until 2030. The main conclusions drawn from the forecasts produced are as follow:

Socioeconomic optimization that forms the consumption goals of economic development leads to surplus grown of GDP and the consumption fund. According to the results of social optimization, when the consumption fund amounts to 
21.5 billion GEL, the population's rational demands for goods and services can be met. Production optimization, on the other hand, with a constant standard of accumulation led to an increase in the consumption fund to 24 billion GEL, that is to unsubstantiated hypertrophy of consumption;

Production optimization disregards the interests of spiritual, scientific-educational, and cultural development. According to its results, the optimal percentage of employment in the scientific-educational and cultural-management sphere in 2030 will amount 21\%; in corresponding conditions this index equal to $28 \%$;

Socioeconomic optimization ensures the necessary increase in room for individual development in the form of free time. According to its results, by 2030 , it may be possible to have a four-day work week with a 7-hour workday.

Based on the calculations carried out with the macroeconomic model we tried to explain how sustainable Georgian economy is and whether Georgian government's current economic policy is adequate and consistent for economic growth. What institutional changes are needed to make the growth of population wellbeing an irreversible process.

Country's economic development depends on not only quantitative but qualitative indicators of growth. Only highquality economic growth can turn into economic development. On the other hand, economic development is of high quality if it is sustainable, accompanied by structural improvements and innovations. We will briefly discuss three important aspects of economic growth that are preconditions to significant progress:

For sustainable economic development inflow of investments is crucial. Significant share of foreign direct investment flowing to Georgia is directed towards non-trade sectors. As local producers lack the capacities needed to locally produce goods that constitute an important part of imports, GDP growth stimulates import growth rather than local real sector. Georgia is characterized by labor force moving from production to service sectors which, on one hand, indicates improved distribution of resources and, on the other hand, indicates that the share of tradable goods is decreased in GDP. In Georgia economic growth is very loosely linked with SME development. Recently, Georgia was characterized by an insignificant increase in labor productivity, however, we significantly lag behind developed countries in terms of this indicator. The indicator denotes the level of labor education and their equipment with modern technologies. In order to improve in this direction, science-related sectors need to develop in Georgia.
Innovations imply generation of scientific-technological achievements and their implementation in production which is a prerequisite for economic progress. Innovation quality is measured by the share of research and development (R\&D) expenditures in GDP which stands at $0.3 \%$ in Georgia, while it is about $3-4 \%$ in developed countries.

One of the indicators of social stability is GDP per capita according to which Georgia takes one of the last positions among transition economy countries. This indicates low advancement in terms of human development. The indicator in Georgia is 5 times less compared to Easter European countries and 10 times less compared to developed states. The reason for this is that Georgian economy underwent a prolonged (5 years) and deep (almost 75\%) contraction. In 2000 Georgian real GDP was only $30 \%$ of its 1990 level. In the coming years economic growth needs to be stimulated and long-term stable growth rates need to be restored. The polarization of population income distribution should be put to end by imposing progressive tax system. In Georgia middle-income group of society has not formed yet $15-7 \%$ in Georgia vis a vis $65-70 \%$ in developed countries), which is still unable to take the role of avant-garde in the society. Reducing inequality, poverty and unemployment is still one of the stressing problems that Georgia is facing. Without solving these problems, it will be impossible to induce social solidarity of the society and ultimately to reach higher levels of wellbeing.

\section{CONCLUSION}

To conclude, economic policy of the Georgian government should be directed towards achieving inclusive growth which will guarantee that economic growth and enhancement is reflected in the wellbeing of every citizen in real terms. Government programs of economic and social development should be detailed in terms of timeline so that people can regularly monitor what has been done. This will help people make proper decisions during elections. Discussed macro model of Georgia's socio-economic development and the obtained results allow us to estimate the current stance of Georgia's economic and social development and timeline for reaching target indicators with concrete parameters. Moreover, it allows us to make estimations by correcting growth trajectory based on existing and attracted resources.

\section{REFERENCES:}

Julakidze, M.G. (2010). A Macro model of Georgia's Socioeconomic Development and its use in forming Economic policy. 11(1), 137-144.CA\&CC Press Sweden.

Papava, V. (2013). Economic Reforms in Post-Communist Georgia: Twenty Years after. Nova Science Publishers.

Papava, V. (2016). Georgia's choice: The European Union or The Eurasian Economic union. Expert Opinion. Georgian Foundation for strategic and international Studies.

Tinbergen, J. (1978). Economic policy: Principles and Design. Amsterdam. 1956, 1978. 478.

Weil, D. N. (2008). Economic Growth. Brown University. Second Edition.

Wooldridge, M. J. (2013). Introductory Econometrics. A Modern Approach. Fifth Edition.

Geostate Database (PC-AXIS Database) of National Statistic Office of Georgia. Retrived from: http://pc-axis.geostat.ge The World Bank Open Date. (2021). https://data.worldbank.org/ 